\title{
Proposta de destinação dos resíduos da construção civil: um estudo de caso na Universidade Federal do Maranhão
}

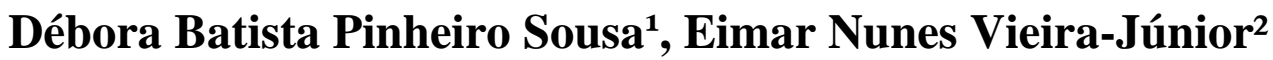

1Universidade Federal do Maranhão. Coordenação do Curso Interdisciplinar em Ciência e Tecnologia. Campus Balsas. Balsas-MA. Brasil (CEP 65800-000). E-mail: deborabpsousa@gmail.com.

${ }^{2}$ Curso de Bacharelado Interdisciplinar em Ciência e Tecnologia. Universidade Federal do Maranhão. Campus Balsas. Balsas-MA. Brasil (CEP 65800-000).

Resumo. A indústria da construção civil é um dos setores que mais têm gerado resíduos dentro das cidades, especialmente pela ausência de políticas públicas de triagem, redução e reciclagem destes resíduos. Neste contexto, o presente artigo tem como objetivo classificar os resíduos de construção e demolição (RCD), da Universidade Federal do Maranhão (UFMA), Campus Balsas, e indicar uma proposta de gerenciamento destes resíduos, para a construção de uma trilha ecológica, com base nos princípios dos 3R's (redução, reutilização e reciclagem). Para tanto, os RCD de três prédios foram classificados de acordo com os critérios da Resolução CONAMA n ${ }^{\circ} 307 / 2002$. Posteriormente, os RCD foram selecionados para construção de cenários de uma trilha ecológica na UFMA, Campus Balsas. A grande maioria dos resíduos encontrados foi da classe A (tijolos, blocos pré-moldados), que foram (re)aproveitados para compor alguns cenários da trilha ecológica. Estes dados são importantes e mostram que a utilização dos 3R's nos planos de gerenciamento da construção civis é válida, tanto para a redução e reutilização do descarte dos RCD, como para reciclagem dos resíduos sólidos.

Palavras-chave: Desenvolvimento sustentável; Trilha Ecológica; Reaproveitamento; Gestão de resíduos.

Abstract. Proposal for destination of construction waste: a case
study of the Federal University of Maranhão. The construction
industry is one of the sectors that have generated the most waste
within cities, especially due to the lack of public policies for sorting,
reducing and recycling these wastes. In this context, the objective of
this article is to classify construction and demolition waste (CDW) of
the Federal University of Maranhão (UFMA), Campus Balsas, and to
indicate a proposal for the management of this waste, for the
construction of an ecological trail, with principles of 3R's (reduction,
reuse and recycling). Therefore, the CDWs of three buildings were
classified according to the criteria of Brazilian CONAMA Resolution
No. 307/2002. Subsequently, the CDWs were selected for the
construction of scenarios of an ecological trail at UFMA, Campus
Balsas. The great majority of the residues found were class A (bricks,
pre-cast blocks), which were used and reused to compose some
scenarios of the ecological trail. These data are important and show
Recebido:

10/07/2017

Aceito:

28/12/2017

Publicado:

31/12/2017

Acesso aberto

Artigo completo

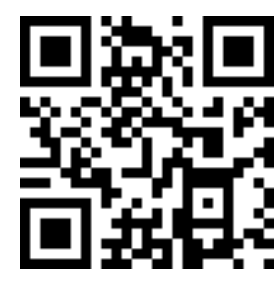

ORCIID

(D) 0000-0002-5104-4869

Débora Batista Pinheiro Sousa

D 0000-0002-0127-7453

Eimar Nunes Vieira

Júnior 
that the use of 3R's in civil construction management plans is valid for both the reduction and reuse of the CDW waste and the recycling of solid waste.

Keywords: Sustainable development; Ecological track; Reutilization; Waste management.

\section{Introdução}

Nas construções realizadas no Município de Balsas, Estado do Maranhão, é visível a geração de grande quantidade de Resíduos de Construção e Demolição (RCD), propiciando assim um desperdício in loco desse material, desde a sua produção até o transporte e deposição deste material. Para tanto, um dos pontos preocupantes relacionados aos resíduos provenientes da construção civil, é a falta de segregação dos diferentes tipos de RCD, tendo em vista que as grandes empresas de engenharia ainda não se preocupam em selecionar os resíduos pela sua classe e importância de reaproveitamento (Mendes et al., 2004). Grande parte dos resíduos gerados é depositada pelas construtoras em terrenos baldios ou lixões, contribuindo até mesmo para a contaminação ambiental através dos produtos tóxicos encontrados nessas localidades (Mendes et al., 2004).

Neste contexto, a ausência de políticas públicas para o descarte de resíduos, é um dos maiores problemas na gestão das cidades, tento em vista que ocasiona impactos negativos na malha urbana, comprometendo o tráfego de pessoas, automóveis, bem como a drenagem urbana (Morais, 2006). Além disso, o acúmulo de resíduos não inertes pode contribuir de modo direto e indireto para o aumento de pragas urbanas que compromete a saúde pública (Morais, 2006).

A construção da Universidade Federal do Maranhão (UFMA), Campus Balsas, foi iniciada em 2013 e ainda não existe uma política de gerenciamento e fiscalização dos resíduos gerados na construção civil por parte do município. Portanto, torna-se necessário à inserção de políticas públicas e ações extensionistas voltadas para o campus, no que diz respeito ao aproveitamento e reciclagem dos resíduos gerados pelas construtoras.

Um novo padrão de construção sustentável mostra que os resíduos podem ser reaproveitados para construção de pavimentação de ruas e avenidas (Bonfim, 2012). Essa nova tecnologia sustentável transforma resíduos de construção em fonte de matéria prima para o uso de novas obras em uma mesma localidade. Dessa forma, torna-se necessário minimizar a quantidade de resíduos de destinação específica, tais como os RCD, seguindo assim a lógica dos três R (reduzir, reutilizar e reciclar) dentro das construções civis (Gouveia, 2012).

Contudo, o princípio dos 3R's, deve ser incentivado através de ações socioeducativas e implementadas paulatinamente nos planos de gerenciamento das construtoras, visando a atitudes de consumo consciente por parte dos encarregados da obra. Neste contexto, a reciclagem é uma medida que deve ser impulsionada, com ações positivas, tais como a coleta seletiva de RCD e a triagem de resíduos. A reutilização, por sua vez, depende da segregação do material, acondicionamento, e disposição final, atos que ainda não são realizados de forma adequada pelas grandes empresas (Evangelista et al., 2010).

Deste modo, além de identificar os resíduos provenientes da construção civil da UFMA, Campus Balsas, o presente trabalho indica uma proposta de destinação dos RCD para construção de cenários alternativos no campus, tal como uma trilha ecológica que está em fase de desenvolvimento no Campus Balsas. Assim, visando o aproveitamento dos RCD no município de Balsas e fazendo cumprir com os marcos legais da Política Estadual de Resíduos Sólidos, o presente trabalho visa a classificação dos resíduos de construção e demolição (RCD) da Universidade Federal do Maranhão, 
Campus Balsas, e indica uma proposta reaproveitamento dos resíduos, para construção de uma trilha ecológica, com base nos princípios dos 3R's (redução, reutilização e reciclagem).

\section{Gestão de resíduos sólidos no Brasil e Estado do Maranhão}

De acordo com a Associação

Brasileira de Empresas de Limpeza Pública e Resíduos Especiais (ABRELPE), 50\% dos resíduos sólidos de todos os conjuntos das atividades antrópicas, são provenientes da indústria da construção civil (Abrelpe, 2011). No Brasil, a Resolução CONAMA $n^{0}$ 307/2002 (Brasil, 2002), a Política Nacional de Saneamento Básico, instituída pela Lei ${ }^{\circ}$ 11.445/2005 (Brasil, 2005), bem como a Política Nacional de Resíduos Sólidos (PNRS), instituída pela Lei $\mathrm{n}^{\circ}$ 12.305/2010 (Brasil, 2010), dão as diretrizes necessárias para regulamentar a gestão de resíduos sólidos no Brasil. A PNRS é a responsável por estabelecer princípios, objetivos, diretrizes, metas e ações que visam a estabelecer regras para todos os órgãos e/ou empresas geradores de resíduos no território brasileiro (Brasil, 2010). No âmbito da construção civil, a PNRS estabelece nas seguintes diretrizes:

- Eliminação de áreas irregulares de disposição final de RCD (botafora) em todo o território nacional.

- Implantação de unidades de recebimento, triagem, transbordo e reservação adequada de RCD (aterros classe A).

- Incremento das atividades de reutilização e reciclagem dos RCD nos empreendimentos em todo 0 território nacional.

- Fomento a medidas de redução da geração de rejeitos e resíduos de construção civil em empreendimentos em todo o território nacional.

- Inventário de Resíduos de Construção Civil. A partir do próximo Censo do IBGE todos os resíduos de construção civil deverão estar inventariados. Os resíduos deverão estar quantificados e especializados.

- Criação de metas e indicadores de redução, coleta, destinação e disposição de resíduos e rejeitos.

O Estado do Maranhão possui o Plano Estadual de Gestão de Resíduos Sólidos (Maranhão, 2012), atendendo a determinação a Lei n ${ }^{0}$ 12.305/2010 (Brasil, 2010), que institui a Política Nacional de Resíduos Sólidos. Para a elaboração do diagnóstico estadual procederam-se levantamentos e análises dos diversos tipos de resíduos gerados no Maranhão e fontes geradoras, sobre o modo de geração, formas de acondicionamento na origem, coleta, transporte, processamento, recuperação e disposição final utilizada atualmente. Desta forma, o Plano Estadual de Gestão apresenta as seguintes diretrizes e estratégias para gestão de resíduos de construção civil:

Diretriz 1. Eliminar as áreas irregulares de disposição final de RCD ("bota-fora") em todo o território estadual.

- Intensificação das ações de monitoramento e fiscalização.

- Articulação interinstitucional entre os órgãos responsáveis pelo controle da gestão de resíduos.

- Busca de aporte de recursos e de linhas de financiamento com a respectiva contrapartida dos municípios voltada à elaboração de projetos e a implantação/ampliação/recuperação de unidades de recebimento, triagem, transbordo e de reservarão adequada de RCD.

- Regularização dos transportadores informais do RCC (condutores de veículos de tração animal, motora, entre outras modalidades de transporte).

Diretriz 2. Fortalecer a gestão dos resíduos sólidos da construção civil e demolição.

- Recebimento pelo órgão ambiental estadual dos Planos de Gerenciamento de Resíduos da Construção Civil e Demolição (RCD). 
- Articulação junto aos órgãos competentes visando à uniformização dos procedimentos referentes ao processo de licenciamento das unidades de RCD, quando couber.

- Recebimento pelo órgão ambiental estadual do Inventário Anual de Resíduos de Construção e Demolição Civil. A apresentação anual do Inventário é obrigatória a partir de dois anos da vigência deste Plano e deverá conter, no mínimo, tipo de obras, especificidade, localização e dados sobre geração, destinação, disposição dos resíduos sólidos.

- Obtenção de indicadores de redução, coleta, destinação e disposição de resíduos e rejeitos.

Diretriz 03. Estimular o desenvolvimento, inovação e aplicação de tecnologias para o aproveitamento dos resíduos sólidos gerados pela construção civil e demolição.

- Estímulo à redução da geração e/ou da utilização de resíduos e rejeitos da construção civil e demolição em empreendimentos em todo o território estadual.

- Articulação com órgãos de pesquisa para o desenvolvimento e inovação tecnológica voltados à reutilização e reciclagem de RCD.

- Estimulo à reutilização e a reciclagem de RCD nas obras e empreendimentos públicos.

- Apoio às ações de difusão tecnológica.

Para tanto, ainda não existe uma política eficiente do gerenciamento dos RCD nos projetos urbanísticos das grandes cidades, em especial para o Estado do Maranhão. Contudo, estudos apontam que em grandes centros urbanos a taxa de geração de RCD variam entre 400 e 700 kg/hab./ano (Evangelista et al., 2010).

Neste contexto, a produção de RCD depende da fase de execução da construção, ou seja, os dados e informações referentes à indústria da construção civil podem ser de utilização limitada, considerando que o ritmo da construção é diretamente relacionado com o contexto histórico da economia (Costa et al., 2014). Esta geração decorre das perdas nos processos construtivos, seja por mau uso da matéria prima disponível e/ou pela mal elaboração de projetos arquitetônicos e de engenharia (Formoso et al., 1998).

Além da proposta de gerenciamento para uma boa administração dos RCD, muitas empresas voltadas para a construção civil ainda não aplicam os princípios dos 3R's (redução, reaproveitamento e reciclagem). Tal medida sustentável, é necessária para o desenvolvimento eficiente de toda cadeia produtiva da indústria da construção civil (Evangelista et al., 2010). Portanto, para uma aplicação mais eficiente dos decretos e leis voltados para a gestão de resíduos sólidos no Brasil e no Estado do Maranhão, é importante uma ação conjunta entre empresas e dos órgãos fiscalizadores dos municípios para a inserção dos princípios dos 3R's nos planos de gerenciamento da construção civil.

\section{Resíduos de Construção e Demolição (RCD)}

Os Resíduos de Construção e Demolição (RCD) são materiais oriundos de construção, reformas, reparos, e demolições de obras de construção civil, sejam eles industrializados ou provenientes de extrações minerais (Brasil, 2002). O Ministério de Meio Ambiente (MMA), por meio do Conselho Nacional de Meio Ambiente - CONAMA (Brasil, 2002) é responsável por estabelecer critérios, regras, diretrizes e procedimentos que devem ser utilizados pelos governos municipais, bem como pelos responsáveis pelo manejo e destinação do RCD.

Neste contexto, a resolução CONAMA, fica responsável por fazer cumprir uma regra simples, quem gera Resíduos de Construção e Demolição (RCD) deve ser responsabilizado pelo transporte e deposição adequada destes materiais (Brasil, 2002). Dessa forma, a prática de reutilizar os RCD, está sendo vista como uma alternativa viável para resolver ou diminuir o problema da ausência de gerenciamento de resíduos da construção civil. Os problemas ambientais 
envolvidos na elevada produção de RCD são visíveis, bem como as inúmeras alterações no meio ambiente, ocorridas devido à má disposição desses resíduos (Carneiro et al., 2001).

Além disso, a resolução CONAMA, obriga que os grandes geradores de RCD tenham um plano de gerenciamento para ausência de produção desses resíduos e/ou a redução, a reutilização, a reciclagem e a destinação final desses RCD. Dentre os matérias com maior taxa de desperdício, destaca-se o gesso. Estima-se que o desperdício desse material chegue até $45 \%$ dentro das construções civis, devido ao rápido processo de endurecimento (Nita et al., 2004). Além desse tipo de resíduo, outros materiais provenientes da construção civil geram uma infinidade de problemas ambientais e econômicos, pois além do alto desperdício é necessário custo elevado para o transporte e destino final destes materiais (Tavares et al., 2010).

A Tabela 1 mostra a classificação dos RCD's de acordo com suas classes e definições (Brasil, 2002; Brasil, 2004; Brasil, 2011; Brasil, 2015).

Tabela 1. Tipos de classes de RCD, segundo a Resolução CONAMA nº 307/2002 (Brasil, 2002; Brasil, 2004; Brasil, 2011; Brasil, 2015).

\begin{tabular}{l|l}
\hline Tipos de resíduos & \multicolumn{1}{c}{ Definição } \\
\hline Classe A & $\begin{array}{l}\text { Os resíduos dessa categoria podem ser reutilizados ou reciclados na própria } \\
\text { construção civil como agregados, por exemplo: de construção, demolição, } \\
\text { reformas e reparos de pavimentação e de outras obras de infraestrutura, } \\
\text { inclusive solos provenientes de terraplanagem e componentes cerâmicos } \\
\text { (Conama, 2002). }\end{array}$ \\
\hline Classe B & $\begin{array}{l}\text { São os resíduos recicláveis para outras destinações, tais como: plásticos, papel, } \\
\text { papelão, metais, vidros, madeiras, embalagens vazias de tintas imobiliárias e } \\
\text { gesso (Conama, 2015). }\end{array}$ \\
\hline Classe C & $\begin{array}{l}\text { Para os resíduos dessa categoria, não foram desenvolvidas tecnologias ou } \\
\text { aplicações economicamente viáveis que permitam a sua reciclagem ou } \\
\text { recuperação (Conama, 2011) }\end{array}$ \\
\hline Classe D & $\begin{array}{l}\text { São resíduos perigosos oriundos do processo de construção (tintas, solventes, } \\
\text { óleos e outros) ou aqueles contaminados ou prejudiciais à saúde oriundos de } \\
\text { demolições, reformas e reparos de clínicas radiológicas, instalações industriais e } \\
\text { outros, assim como telhas e demais objetos e materiais que contenham produtos } \\
\text { nocivos à saúde (Conama, 2004). }\end{array}$ \\
\hline
\end{tabular}

Fonte: Brasil (2002; 2004; 2011; 2015).

Além da classificação, um bom plano de gerenciamento destinado a construção civil deve levar em consideração a destinação dos RCD's (Tabela 2). Tais práticas visam à sustentabilidade das construções civis, no que diz respeito ao correto descarte e/ou aproveitamento dos resíduos.

Deste modo, a redução dos RCD é um dos objetivos prioritários na gestão de resíduos sólidos da construção civil (Fernandes, 2013) e um ponto de extrema relevância no momento da elaboração do plano de gerenciamento da construção civil. Para tanto, torna-se necessário a implementação de projetos inovadores, que utilizem a política dos 3R's desde o início até o término das obras. Além disso, a escolha de materiais que sejam ambientalmente sustentáveis e o seu destino correto também deve ser levado em consideração nas construções civis (Fernandes e Silva-Filho, 2015). 
Tabela 2. Destinação de RCD, segundo a Resolução CONAMA nº 307/2002 (Brasil, 2002, 2012).

\begin{tabular}{l|l}
\hline Tipos de resíduos & \multicolumn{1}{c}{ Destinação } \\
\hline Classe A & $\begin{array}{l}\text { Os resíduos dessa categoria deverão passar por um processador de reutilização } \\
\text { e/ou reciclagem na forma de agregados ou encaminhados a um aterro de } \\
\text { resíduos classe A, de modo que os resíduos possam ser utilizados futuramente } \\
\text { (Brasil, 2012). }\end{array}$ \\
\hline Classe B & $\begin{array}{l}\text { Os resíduos dessa categoria são reutilizados, reciclados ou encaminhados a } \\
\text { áreas de armazenamento temporário, de modo que os resíduos possam ser } \\
\text { utilizados futuramente (Brasil, 2002). }\end{array}$ \\
\hline Classe C & $\begin{array}{l}\text { São resíduos que passam por um processo de armazenamento, transporte e } \\
\text { destino de acordo com as normas técnicas específicas (Brasil, 2002). }\end{array}$ \\
\hline Classe D & $\begin{array}{l}\text { Os resíduos dessa categoria são armazenados, transportados e destinados de } \\
\text { acordo com as normas técnicas específicas (Brasil, 2012). }\end{array}$ \\
\hline
\end{tabular}

Fonte: Brasil (2002; 2012).

Assim, visando a políticas públicas para o Município de Balsas, o presente trabalho propõe uma alternativa de destinação final dos RCD provenientes da construção dos prédios da UFMA, Campus Balsas, baseado no princípio dos 3R's.

\section{Materiais e métodos}

\section{Área de estudo}

O Campus da UFMA, no Município de Balsas, está localizado nas margens da Rodovia MA-140, km 7. O diagnóstico e classificação dos RCD foi realizado no canteiro de obras da UFMA, Campus Balsas (Figura 1).

Para tanto, os resíduos de três prédios (sala de aula, administrativo e laboratórios de ensino) foram fotografados e classificados de acordo com a Resolução do CONAMA no 307/2002 (Brasil, 2002).

\section{resíduos}

\section{Classificação e destinação dos}

Para realizar a caracterização qualitativa dos RCD na construção da UFMA, Campus Balsas, foi utilizado método de amostragem de pilha ou monte, segundo a ABNT 10007 (ABNT, 2004). A amostragem consistiu na seleção de materiais, que tivessem as condições mínimas de serem reaproveitados para a construção da trilha ecológica. A triagem foi realizada separando os materiais por classe, e, posteriormente, os mesmos foram transportados para os locais de desenvolvimento e construção da trilha ecológica.

\section{Resultados}

A maioria dos RCD, especialmente chapiscos e restos de tijolos quebrados, foram encontrados no prédio administrativo. Tal diferença em relação aos outros prédios foi constatada pela longa duração na construção desse bloco. No prédio de sala de aulas e laboratórios de ensino foram encontrados (em maior quantidade) restos de madeiras, telhas de fibrocimento e estruturas metálicas, tais como baldes, tambores e carros de mãos que não foram reaproveitados. A Tabela 3 indica os resíduos encontrados nos três prédios da UFMA, Campus Balsas. 

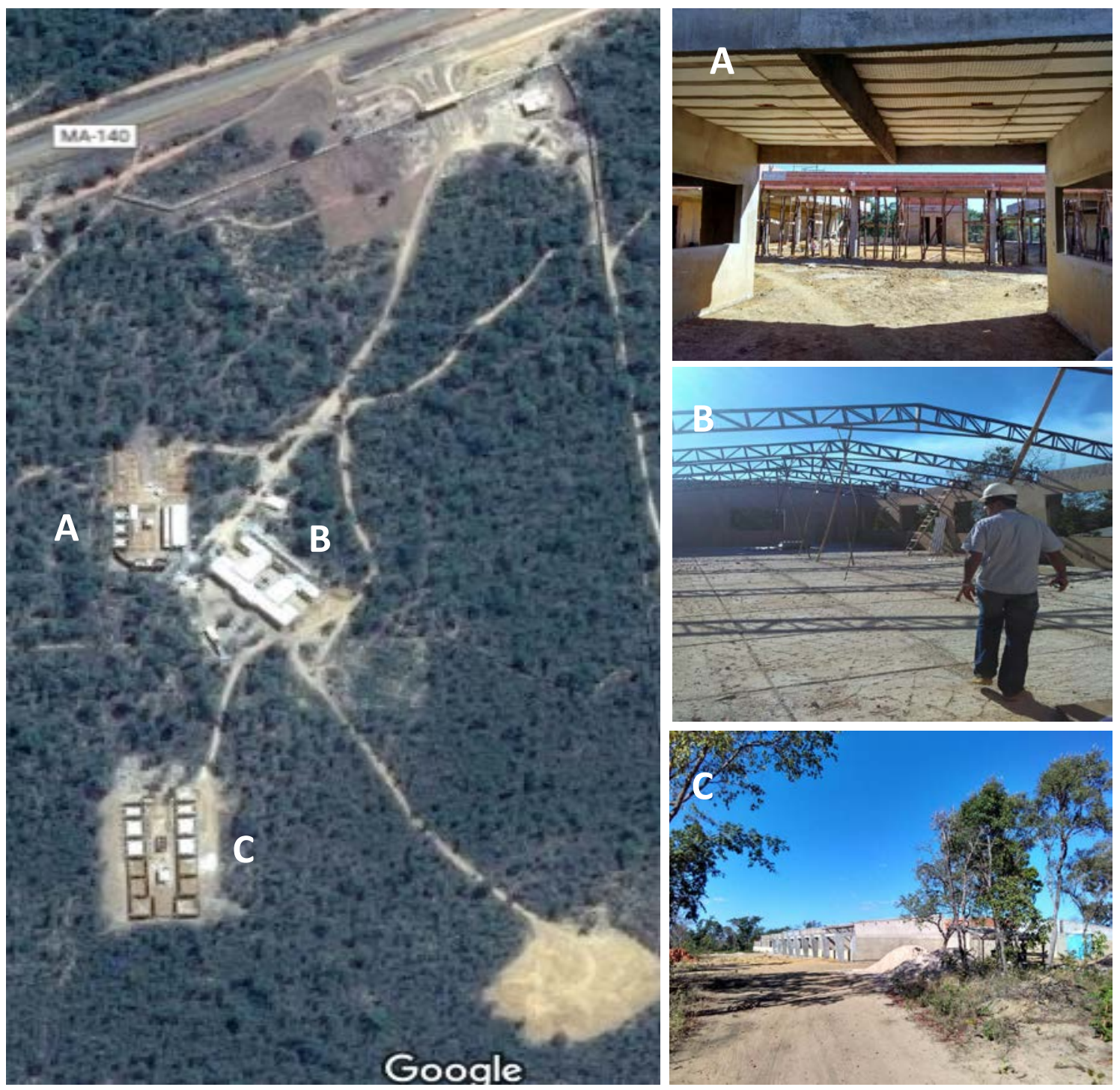

Figura 1. Localização da Universidade Federal do Maranhão, Campus Balsas. (A) Blocos de sala de aula, (B) Administrativo e (C) Laboratórios de Ensino. Fonte: Google.

Tabela 3. RCD diagnosticados na construção da Universidade Federal do Maranhão, Campus Balsas.

\begin{tabular}{l|l}
\hline Classe dos resíduos & Resíduos encontrados na construção civil da UFMA/Campus Balsas \\
\hline \multirow{4}{*}{ Classe A } & $\bullet$ Tijolos. \\
& $\bullet$ Chapiscos. \\
& $\bullet$ Blocos pré-moldados. \\
& • Telhas de fibrocimento. \\
& • Concreto. \\
& $\bullet$ Tubulações e forros de PVC. \\
\hline \multirow{3}{*}{ Classe B } & $\bullet$ Papel e papelão. \\
& $\bullet$ Metais (baldes, tambores, carcaça de carro de mão). \\
& $\bullet$ Troncos de árvores e madeirites. \\
& $\bullet \quad$ Estruturas metálicas. \\
\hline
\end{tabular}


Dentre os materiais que foram destinados para o reaproveitamento na própria obra estão os RCD de classe A (tijolos, chapiscos, argamassa, telhas e etc.), sobretudo os resíduos de alvenarias e concretos, que são reutilizados como aterro nas obras do campus. Além disso, os pregos foram reutilizados para serem reutilizados em outras etapas da construção.

Contudo, os resíduos que não são aproveitados na obra, são destinados para
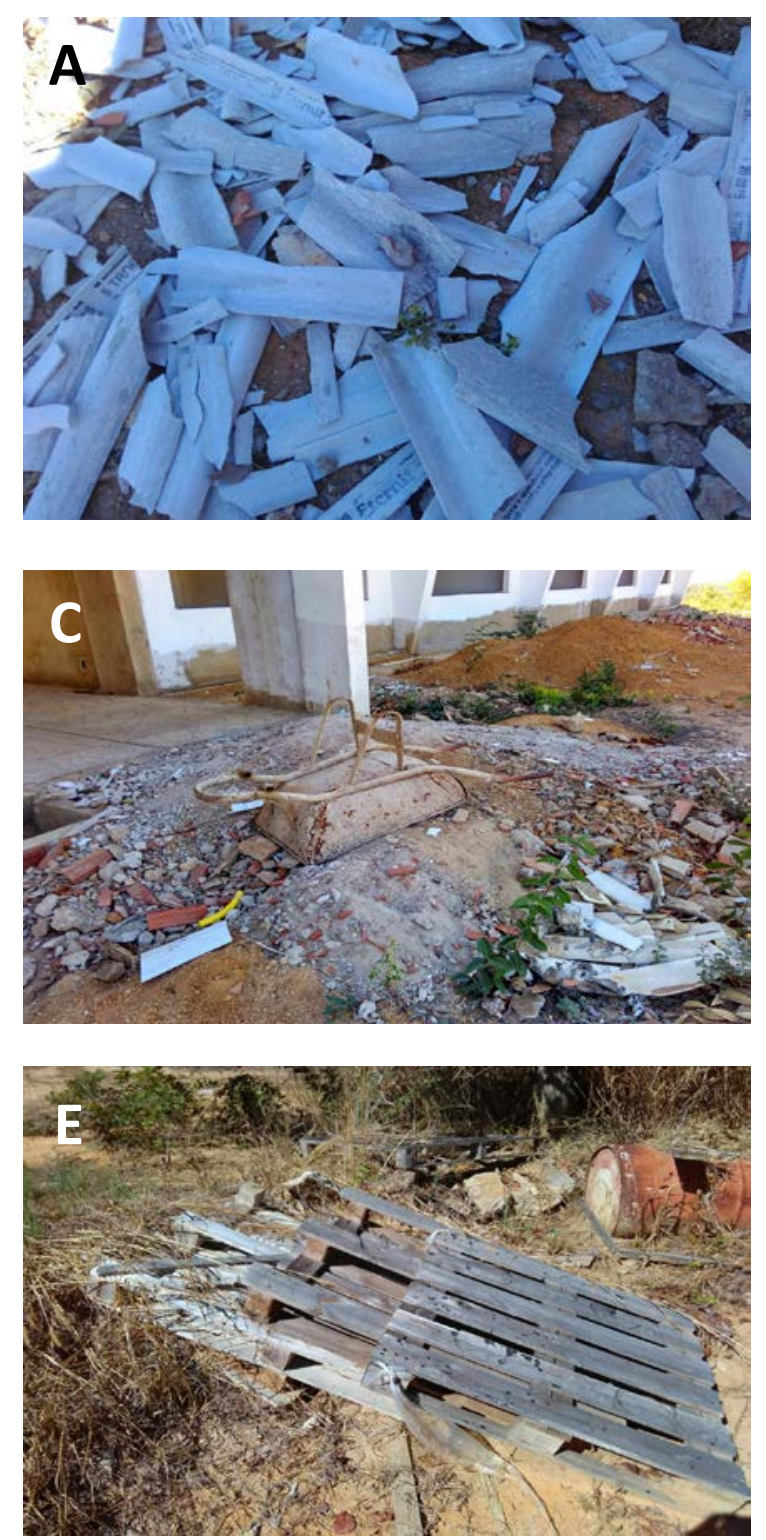

terrenos baldios e lixões do Município de Balsas. Tal processo de reutilização de resíduos da construção civil, foi realizado para compor alguns cenários da trilha ecológica da UFMA, Campus Balsas. A Figura 2 mostra os resíduos de demolição e equipamentos (sucateados na construção) que estão sendo destinados para a construção da trilha ecológica.
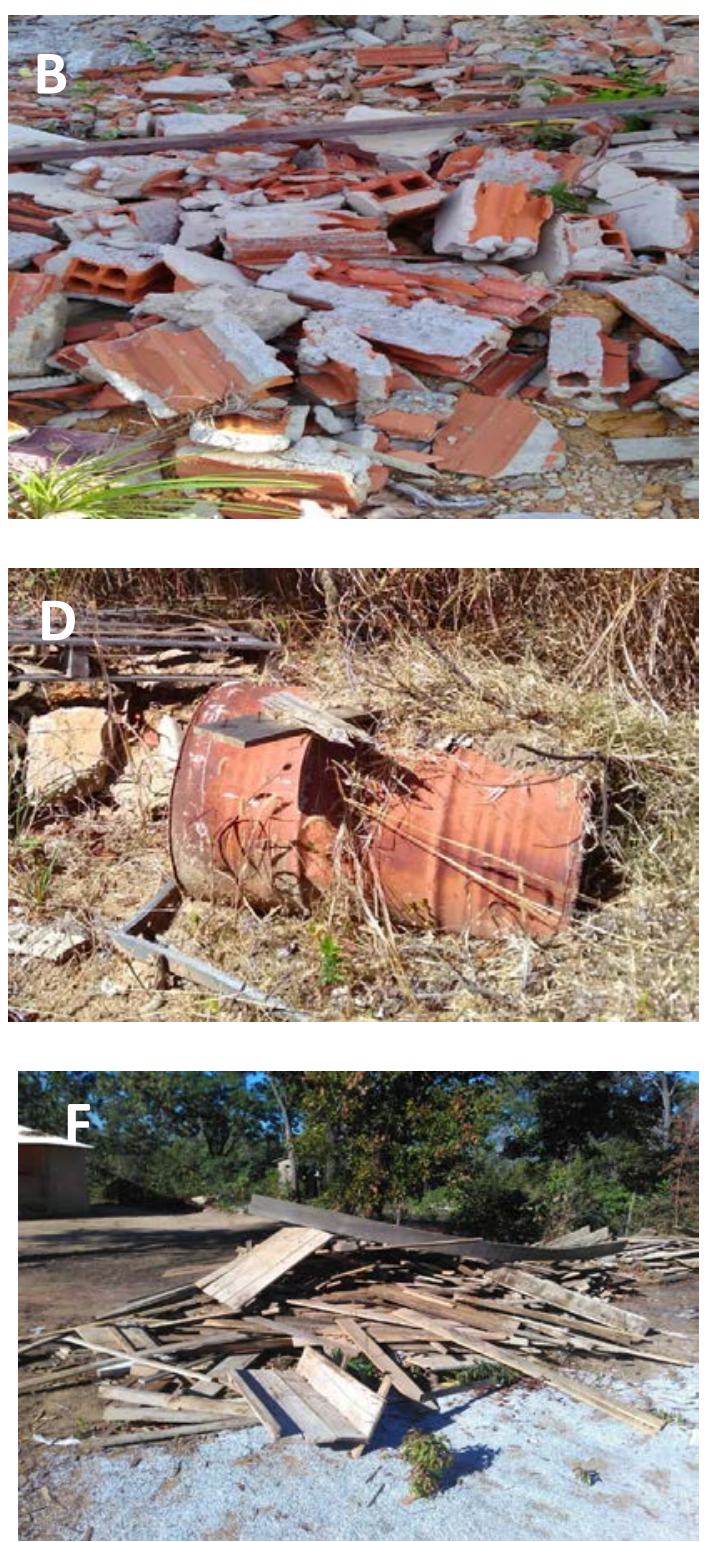

Figura 2. Resíduos de Construção e Demolição (RCD) encontrados na construção civil da UFMA, Campus Balsas. A) Telhas de fibrocimento; B) Tijolos; C) Carrinho de mão e Chapisco de reboco; D) Tambores de ferro; E e F) Madeiras. 
Como proposta de gerenciamento, muitos dos resíduos de classe A (resquícios de telha de fibrocimento, chapiscos, e resíduos de tijolos) foram destinados para a compactação de algumas partes que irão compor o caminho da trilha ecológica. Além disso, resíduos de sucata (tambores de tinta e carrinhos de mão) foram destinados para confecção de lixeiras e canteiro de plantas e flores. Os restos de madeiras serão reaproveitados e reciclados na fabricação de bancos que serão colocados nas praças que irão compor a trilha ecológica.

\section{Discussão}

O gerenciamento dos Resíduos de Construção e Demolição (RCD) é um grande desafio para as empresas do setor da construção civil e uma das principais formas de reduzir os impactos ambientais das grandes cidades (Fernandes, 2013). Para tanto, para um correto gerenciamento dos RCD, é necessário conhecer os diversos processos durante todo o ciclo de vida de um produto, desde a sua fabricação até a sua reciclagem e reutilização (Oliveira et al., 2008; Santos et al., 2011; Fernandes, 2013).

Além disso, para o gerenciamento dos RCD é necessário conhecer as reais prioridades e destino final dos resíduos, visando diminuir o desperdício no canteiro de obras (Tessaro et al., 2012). Dentre as possibilidades, a reutilização de materiais é um dos fatores mais importantes dentro das obras, pois tal medida representará menor consumo de energia e de água que a reciclagem e, consequentemente, uma menor taxa de emissão de gases poluentes (Baptista-Junior e Romanel, 2013).

Dessa forma, o tratamento dos RCD exige uma nova abordagem dentro das construções civis, e, nesse artigo é ressaltada a necessidade de empregar práticas dos 3R's no próprio canteiro de obra da UFMA, Campus Balsas, com o intuito de minimizar os impactos dos RCD no meio ambiente. Dessa forma, os materiais provenientes da construção dos prédios da UFMA, Campus Balsas, foram destinados para reaproveitamento e/ou reciclagem para a construção de uma trilha ecológica dentro do próprio campus. Tal prática de é uma alternativa sustentável e ecologicamente relevante na utilização de materiais da construção civil.

Quando discutimos sobre reaproveitamento de RCD nos canteiros de obras, podemos destacar o (re)aproveitamento de RCD (Obras Sustentáveis, 2016). Nesse caso, sugere-se que antes da demolição seja realizado um desmonte dos materiais que possam ser reaproveitados, tais como madeiras, portas, peças de banheiro e janelas (Obras Sustentáveis, 2016) para que possam ser vendidos ou utilizados em outras partes da construção. Uma das possibilidades de redução, dentro obra, é solicitar ao fornecedor de um material o mais acabado possível, visando assim a evitar o desperdício ao longo de ouras fase de execução da obra (Obras Sustentáveis, 2016).

Contudo, a reciclagem dos RCD, é uma alternativa ainda pouco utilizada pelas empresas que recebem os resíduos das construtoras. Nesse caso, quando as empresas de construção civil realizam tal prática, basicamente é realizada com a reintrodução desses resíduos em diferentes etapas da obra. Para John e Agopyan (2001), do ponto de vista técnico as possibilidades de reciclagem dos resíduos variam de acordo com a sua composição. Quase a totalidade da fração cerâmica pode ser beneficiada como agregado com diferentes aplicações conforme sua composição específica. As frações compostas predominantemente de concretos estruturais e de rochas naturais podem ser recicladas como agregados para a produção de concretos estruturais. Para tanto é necessário que isso ocorra dentro de um processo produtivo que envolva gasto de energia, gerando assim um novo produto idêntico ou não àquele que lhe deu origem (Obras Sustentáveis, 2016). No caso do reaproveitamento de materiais sucateados (tambores, e carros de mão) da construção da UFMA, Campus Balsas, muitos foram destinados para reciclagem e um novo tratamento de pintura para servir como itens de jardinagem para a trilha ecológica. 
Esses dados indicam que o (re) aproveitamento e a reciclagem de RCD é de extrema relevância para minimizar os impactos gerados pela construção no Município de Balsas. Além disso, a proposta de destinação dos RCD do presente no artigo é de extrema relevância para minimizar os impactos ambientais e visuais no campus. Dessa forma, o planejamento e o gerenciamento dos RCD baseado no princípio dos 3R's é uma alternativa eficaz para minimizar 0 desperdício de resíduos no seguimento da construção civil.

\section{Conclusões}

Discutir ideias sustentáveis e os princípios dos 3R's (reduzir, reaproveitar e reciclar) na construção civil é de extrema relevância para a elaboração de projetos de gerenciamento dos resíduos de construção e demolição (RCD). A maioria dos RCD provenientes da construção civil da UFMA, Campus Balsas, é de classe A e, de acordo com a legislação podem ser reaproveitados e reciclados na própria construção ou com materiais alternativos.

Uma grande parte dos materiais diagnosticados e classificados foram reaproveitados em várias fases da construção e destinados para compor cenários de uma trilha ecológica no campus. Além disso, restos de sucatas e madeiras foram reaproveitados para construção de componentes na trilha. Assim, a alternativa de tratamento dos RCD, com base nos 3R's, é de extrema relevância para minimizar os impactos ambientais no Brasil, especialmente no município de Balsas, que ainda não possui uma fiscalização eficiente em relação destino dos RCD.

\section{Agradecimentos}

Agradecemos ao diretor da Universidade Federal do Maranhão (UFMA), Campus de Balsas, pela ordem de serviço para a realização deste trabalho e a toda equipe técnica da construção dos prédios da UFMA, Campus de Balsas.

\section{Declaração de conflito de interesse}

Os autores declaram não haver conflito de interesse.

\section{Referências}

Abrelpe - Associação Brasileira de Empresas de Limpeza Pública e Resíduos Especiais. Panorama de Resíduos Sólidos no Brasil. São Paulo: Abrelpe, 2011.

ABNT - Associação Brasileira de Normas Técnicas. ABNT NBR 10007 - Resíduos sólidos: amostragem de resíduos sólidos. 2. ed. Rio de Janeiro: ABNT, 2004.

Baptista-Junior, J. V.; Romanel, C. Sustentabilidade na indústria da construção: uma logística para reciclagem dos resíduos de pequenas obras. urbe. Revista Brasileira de Gestão Urbana, v. 5, n. 2, p. 27-37, 2013. https://doi.org/10.7213/urbe.05.002.SE02

Brasil. Lei $n^{\circ}$ 11.445, de 5 de janeiro de 2005. Estabelece diretrizes nacionais para 0 saneamento básico. Disponível em: <http://www.planalto.gov.br/ccivil_03/_ato2007 -2010/2007/lei/l11445.htm>. Acesso em: 26 nov. 2016.

Brasil. Lei $\mathbf{n}^{0}$ 12.305, de 2 de agosto de 2010. Institui a Política Nacional de Resíduos Sólidos. Disponível em: <http://www.planalto.gov.br/ ccivil_03/_ato2007-2010/2010/lei/l12305.htm>. Acesso em: 26 nov. 2016.

Brasil. Portaria SIT $\mathbf{n}^{\mathbf{0}}$ 296, de 16 de dezembro de 2011. NR 18: condições e meio ambiente de trabalho na indústria da construção. Disponível em: <http://www.trtsp.jus.br/ geral/tribunal2/LEGIS/CLT/NRs/NR_18.html>. Acesso em: 26 nov. 2016.

Brasil. Resolução CONAMA no ${ }^{0}$ 307, de 5 de julho de 2002. Disponível em: <http://www.mma.gov.br/port/conama/res/res02 /res30702.html>. Acesso em: 29 maio 2016.

Brasil. Resolução CONAMA no ${ }^{\circ}$ 348, de 17 de agosto de 2004. Disponível em: <http://www.mma.gov.br/port/conama/legiabre. cfm?codlegi=449>. Acesso em: 29 maio 2016.

Brasil. Resolução CONAMA no ${ }^{\circ 31}$, de 24 de maio de 2011. Disponível em: <http://www.mma.gov.br/port/conama/legiabre. cfm?codlegi=649> . Acesso em: 29 maio 2016.

Brasil. Resolução CONAMA no 448, de 18 de janeiro de 2012. Disponível em: $<$ http://www.mma.gov.br/port/conama/legiabre. cfm?codlegi=672>. Acesso em: 29 maio 2016. 
Brasil. Resolução CONAMA n 469, de 29 de julho de 2015. Disponível em: <http://www.mma.gov.br/port/conama/legiabre. cfm?codlegi=714>. Acesso em: 29 maio 2016.

Bonfim, V. Pavimentação sustentável: reaproveitamento do resíduo da construção civil e de material fresado com espuma de asfalto. Anais da XVIII Reunião de Pavimentação Urbana, São Luís, 2012.

Carneiro, A. P.; Burgos, P. C.; Alberte, E. P. V. Uso do agregado reciclado em camadas de base e sub-base de pavimentos. Salvador: EdUFBA/Caixa Econômica Federal, 2001.

Costa, R. G.; Athayde Júnior, G. B.; Oliveira, M. M. Taxa de geração de resíduos da construção civil em edificação na Cidade de João Pessoa. Ambiente Construído, v. 14, n. 1, p. 127-137, 2014. https://doi.org/10.1590/ S1678-86212014000100011

Evangelista, P. P. A.; Costa, D. B.; Zanta, V. M. Alternativa sustentável para destinação de resíduos de construção Classe A: sistemática para reciclagem em canteiros de obra. Ambiente Construído, v. 10, n. 3, p 23-40, $2010 . \quad$ https://doi.org/10.1590/S167886212010000300002

Fernandes, M. P. M.; Silva-Filho, L. C. P. Segurança do trabalho do RCC inerte. Ambiente Construído, v. 15, n. 2, p. 113-126, $2015 . \quad$ https://doi.org/10.1590/s167886212015000200017

Fernandes, M. P. M. Apreciação de boas práticas visando à geração de um modelo para gestão municipal dos resíduos da construção civil. Porto Alegre: Universidade Federal do Rio Grande do Sul, 2013. (Tese de doutorado).

Formoso, C. T.; Jobim, M. S. S.; Costa, A. L.; Rosa, F. P. Perdas de materiais na construção civil: um estudo em canteiros de obras no Estado do Rio Grande do Sul. Anais do Congresso Latino Americano de Tecnologia e Gestão na Produção de Edifícios: Soluções para o Terceiro Milênio, São Paulo, 1998. p. 299307.

Gouveia, N. Resíduos sólidos urbanos: impactos socioambientais e perspectiva de manejo sustentável com inclusão social. Ciência \& Saúde Coletiva, v. 17, n. 6, p. 1503-1510, $2012 . \quad$ https://doi.org/10.1590/S141381232012000600014

John, V. M.; Agopyan, V. Reciclagem de resíduos da construção. São Paulo: USP, 2001.
Maranhão. Plano Estadual de Gestão dos Resíduos Sólidos do Maranhão - PEGRS-MA. 2012. Disponível em: <https://observatoriopnrs. files.wordpress.com/2014/11/maranhc3a3oplano-estadual-de-resc3adduos-sc3b3lidos.pdf $>$. Acesso em: 26 nov. 2016.

Mendes, T. A.; Rezende, L. R.; Oliveira, J. C.; Guimarães, R. C.; Camapum de Carvalho, J.; Veiga, R. Parâmetros de uma pista experimental executada com entulho reciclado. Anais da XXXV Reunião Anual de Pavimentação, Rio de Janeiro, 2004.

Morais, G. M. D. Diagnóstico da deposição clandestina de resíduos de construção e demolição em bairros periféricos de Uberlândia: subsídios para uma gestão sustentável. Uberlândia: Universidade Federal de Uberlândia, 2006. (Dissertação de Mestrado).

Nita, C.; Pileggi, R. G.; Cincotto, M. A.; John, V. M. Estudo da reciclagem do gesso de construção. Anais da X Conferência LatinoAmericana de Construção Sustentável e Encontro Nacional de Tecnologia do Ambiente Construído, 18-21 de julho de 2004, São Paulo, 2004.

Oliveira, P. E. S.; Oliveira, J. T. R.; Ferreira, S. R. M. Avaliação do desempenho do concreto com uso de agregado de resíduos de construção e demolição - RCD. Anais do L Congresso Brasileiro de Concreto, Salvador, 2008.

Obras Sustentáveis. Disponível em: $<$ http://obrassustentaveis.com.br/residuos>.

Acesso em: 03 set. 2016.

Portal Resíduos Sólidos. Disponível em: $<$ http://www.portalresiduossolidos.com/classific acao-dos-residuos-da-construcao-civil-nobrasil/>. Acesso em: 23 jul. 2016.

Santos, M. F. N.; Battistelle, R. A. P.; Hori, C. Y.; Julioti, P. S. Importância da avaliação do ciclo de vida na análise de produtos: possíveis aplicações na construção civil. Gestão da Produção, Operações e Sistemas, v. 6, n. 2, p. 57-73, 2011. Disponível em: $<$ http://revista.feb.unesp.br/index.php/gepros/art icle/view/882/369>. Acesso em: 03 set. 2016.

Tavares, Y. V. P.; Lordsleem Júnior, A. C.; Schmitz, I. B. T. A.; John, V. M. Reaproveitamento do resíduo de gesso na execução de revestimento interno de vedação vertical. Ambiente Construído, v. 10, n. 1, p. 103-119, 2010. https://doi.org/10.1590/ S1678-86212010000100006 
Tessaro, A. B.; Sá, J. S.; Scremin, L. B. Quantificação e classificação dos resíduos procedentes da construção civil e demolição no Município de Pelotas, RS. Ambiente

Construído, v. 12, n. 2, p. 121-130, 2012. https://doi.org/10.1590/S1678-86212012000200008

Informação da Licença: Este é um artigo Open Access distribuído sob os termos da Licença Creative Commons Attribution, que permite uso irrestrito, distribuição e reprodução em qualquer meio, desde que a obra original seja devidamente citada. 